\title{
Lightning Injury in Children
}

\section{Kadeejath Thasneem ${ }^{1} \cdot$ Vinod H Ratageri $^{1}$ (I) - S. R. Fattepur ${ }^{1}$}

Received: 26 February 2019 / Accepted: 28 May 2019 / Published online: 11 June 2019

(C) Dr. K C Chaudhuri Foundation 2019

To the Editor: Lightning is an uncommon but potentially disastrous cause of injury [1]. The clinical manifestation of lightning strike can range from mild superficial skin burns to severe multiorgan dysfunction and death depending upon intensity and duration of exposure $[2,3]$. Herein we report two cases of lightning and its aftermath in children.

Case 1: A 12-y-old boy was injured when lightning struck him while standing underneath a tree. The child had loss of consciousness (Glasgow coma scale - 12/15) but vitals were normal. He had an entrance wound at right occipital area and exit wound at left lower leg with first degree superficial burns. Other systems were normal. The ECG showed ST elevation and tall $\mathrm{T}$ waves in precordial and lateral leads, however, 2D echo was normal. CK-MB was high (157 IU/L). Child's condition improved with supportive care. Serial ECG after $1 \mathrm{wk}$ showed no obvious abnormality.

Case 2: A 6-y-old girl was injured over the abdomen and chest following lightning strike when it hit initially over an electric pole and reflected on her. The child had one episode of vomiting and convulsion without loss of consciousness. When the child was brought to the emergency room, she was drowsy but her vitals were normal. She had cutaneous burns over the abdomen and singeing of hair with burnt clothes. Other systems were normal. CT scan brain showed mild cerebral edema. The child improved with supportive care.

Lightning strike injuries are rare, and mostly because of an indirect electrical injury. The overall fatality rate is about 0.25 per million population per year in India [4] and the peak months are June-September [5]. The most deadly complication of lightning is cardiac arrest, and one of our case had evidence of myocardial injury in ECG. Lightning causes a massive DC "counter shock", which simultaneously depolarizes the entire myocardium and also chest muscle paralysis and suppression of medullary respiratory centers $[2,6]$.

In our second case, child had convulsion following lightning. In a study by Ritenour et al., CT or MRI showed cerebral edema as a common finding [2]. Lightning injury may be associated with long term neuropsychological impairment [2].

Thus, one should consider lightning when kids are found lying unconscious outdoors, especially during the rainy season.

\section{Compliance with Ethical Standards}

Conflict of Interest None.

\section{References}

1. Nguyen BH, MacKay M, Bailey B, Klassen TP. Epidemiology of electrical and lightning related deaths and injuries among Canadian children and youth. Inj Prev. 2004;10:122-4.

2. Ritenour AE, Morton MJ, McManus JG, Barillo DJ, Cancio LC. Lightning injury: a review. Burns. 2008;34:585-94.

3. Sumangala CN, Kumar MP. Lightning death: a case report. J Indian Acad Forens Med. 2015;37:93-5.

4. Singh O, Singh J. Lightening fatalities over India: 1979-2011. Meteorol Appl. 2015;22:770-8.

5. Nizamuddin S. Deaths caused by lightning in India. Weather. 1992;47:366-7.

6. Tadler M, Rüegg E, Niquille M, et al. Multi-organ injuries due to a lightning strike: a case report highlighting the importance of a multidisciplinary approach. Case Reports Plast Surg Hand Surg. 2017;4: $1-4$.

Publisher's Note Springer Nature remains neutral with regard to jurisdictional claims in published maps and institutional affiliations.
Vinod H Ratageri

ratageri@rediffmail.com

1 Department of Pediatrics, Karnataka Institute of Medical Sciences, Hubballi, Karnataka, India 